\title{
In honor of Professor Sylvia Daunert
}

\author{
Aldo Roda ${ }^{1}$ \\ Published online: 20 July 2016 \\ (C) Springer-Verlag Berlin Heidelberg 2016
}

I am delighted to write an editorial in appreciation of Sylvia Daunert, a former Editor of Analytical and Bioanalytical Chemistry. I am writing this editorial in honor of Sylvia as one of her $\mathrm{ABC}$ co-editors, but perhaps even more as her friend (Fig. 1).

Sylvia is a unique 'wonder woman,' who combines vitality and creativity with great professional skill and scientific rigor. This is reflected in her excellent international reputation: Sylvia has been honored with numerous awards from the National Science Foundation, the National Institutes of Health, the American Chemical Society, and other professional and private institutions. She is also an elected member of the Real Academia Nacional de Farmacia of Spain and Elected Academic D'Honor, Reial Acadèmia de Farmàcia de Catalunya.

The subject of over 250 publications and patents, Sylvia's work has been highlighted by both the scientific media and the popular press. She is currently the Lucille P. Markey Chair of Biochemistry and Molecular Biology at the Miller School of Medicine, and the Associate Director of the JT Macdonald Foundation Biomedical Nanotechnology Institute of the University of Miami. Prior to joining the University of Miami, Sylvia was the Gill Eminent Professor of Chemistry and Professor of Pharmaceutical Sciences at the University of Kentucky. A former Fulbright Scholar, she earned a Pharm.D. and a Ph.D. in Bioanalytical Chemistry, both from the University of Barcelona, and a Master of Science in Medicinal Chemistry from the University of Michigan at Ann Arbor.

Aldo Roda

aldo.roda@unibo.it

1 Department of Chemistry, G. Ciamician, Alma Mater Studiorum, University of Bologna, Bologna, Italy
I first met Sylvia in 1998 at the 10th International Symposium on Bioluminescence and Chemiluminescence (ISBC), which I organized in Bologna, Italy. Sylvia presented her excellent work on genetically engineered bioluminescent bacteria and cells as biosensors for detecting the toxicity of toxic metals and other analytes relevant for clinical and environmental sciences. On talking with her, Sylvia's energy and creativity were immediately apparent, and I realized that it would be important for my group and my young fellows to collaborate with her. This fruitful collaboration led to the joint publication of interesting papers on the use of photoproteins, such as aquorin, to develop new sensitive immunoassays. I began to send my doctorate students to her laboratory in Lexington, Kentucky. Mara Mirasoli spent more than a year there, as did Elisa Michelini. Patrizia Pasini decided to stay in Lexington and has been working with Sylvia for many years now. Mara, Elisa, and Patrizia are highly successful scientists; Drs. Mirasoli and Michelini hold academic positions at the University of Bologna and Dr. Pasini at the College of the Bahamas.

In Kentucky, Sylvia worked closely with the Faculty of Engineering, jointly designing devices, and with physicians who tested the devices in their clinics. Her work on the analytical use of aquorin and green fluorescent protein (GFP) in some way anticipated the research goals of the 2008 Chemistry Nobel Prize, awarded to O. Shimomura, M. Chalfie, and R.Y. Tsien for discovery and development. Now based in Miami, Sylvia continues to believe in extensive interdisciplinary collaboration and is planning joint projects between departments at the Miller School as well as the College of Arts and Science and Engineering at the Coral Gables campus. She has also established several important international collaborations.

The Daunert group designs photoproteins and bacteria that are genetically engineered to produce light of different colors and at different times. These can help detect levels of target molecules, which are either clinically or environmentally 


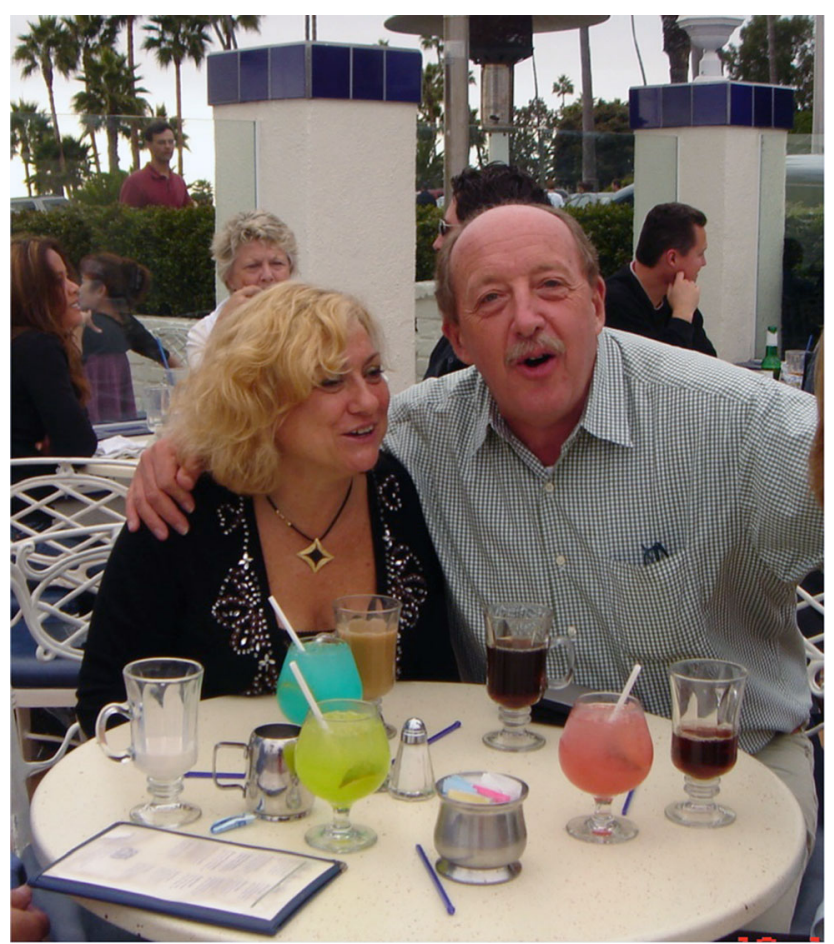

Fig. 1 Sylvia Daunert and Aldo meeting in Newport Beach, CA, in October 2006

important. For example, using protein-based biosensors, Sylvia worked on drug delivery systems or "smart pills," tiny devices that could be placed in the abdomen to help control diabetes by sensing levels of glucose and delivering appropriate amounts of medication in response. In another configuration, her team is developing catheters capable of continuous monitoring of glucose in ICU patients. The photoprotein technology is now reaching its peak, and the engineered bioluminescent proteins are explored for use in early detection and imaging of tumors by employing simple digital cameras. Her team's research efforts are also focused on the development of microfluidics and point-of-care devices for space exploration, global health and emerging diseases, and environmental analysis. Finally, an area of current interest of Sylvia's group is in regenerative medicine, and to that end they design and prepare nanocarriers for targeted delivery of therapeutic agents, such as nucleic acids, proteins, and stem cells. Sylvia has many patents covering the different areas of her group's discoveries.

Sylvia has a wide vision of science and has written: "We live in an increasingly global environment and I want students to communicate and integrate with their peers around the world... Miami is already a cultural melting pot and I hope to introduce similar global research projects at the Miller School." Mentoring and teaching others how to mentor are core elements of Sylvia's teaching philosophy.
Sylvia is indefatigable in her service to the wider scientific community. She serves on several scientific advisory boards of biotechnology companies and research organizations, and has been a member of numerous National Institutes of Health, Department of Energy, NASA, Department of Defense, and the National Science Foundation special review panels, among others. She is Executive Editor of Analytical Biochemistry, serves as part of the editorial team of Annual Reviews in Analytical Chemistry, and has been a member of the editorial advisory boards of Bioconjugate Chemistry and several other journals.

Sylvia realized early on that the 'bioanalytical' realm of the analytical sciences would be of great strategic importance for the future. She thus made great efforts to promote this part of Analytical and Bioanalytical Chemistry's title. On a more personal note, as one of ABC's founding editors, she put forward my name for consideration, first as a Regional Editor and then as an Editor of ABC. For this, Sylvia has my sincere thanks.

Sylvia was born in Barcelona, but now lives in Miami, where her husband, Leonidas G. Bachas, is the Dean of the University of Miami's College of Arts and Sciences. They have three children, Stephanie, Philip, and Sophie. When Stephanie was diagnosed at age 13 with Crohn's disease, Sylvia faced the difficult challenge of balancing her duties and responsibilities as an important scientist against those of a parent. Nevertheless, Sylvia remained positive and never stopped working. Despite this great adversity and inspired by the needs for better tools for the management of autoimmune diseases, such as Crohn's Disease, she continued to produce new and fascinating ideas that led to concrete bioanalytical concepts and devices. For example, Sylvia recognized early on the importance of the microbiome in human health and, in that regard, 10 years ago her group was the first to develop biosensors for detection of bacterial quorum sensing molecules and demonstrate the presence of these microbiome signaling molecules in physiological fluids. This led to a series of enabling technologies that are being evaluated in the clinic for management of diseases where the microbiome plays a role.

For all the above reasons, Sylvia is an inspiration for scientists working on bioluminescence and applied biochemistry. Her lectures and consultations are always appreciated and of great value, particularly for young scientists starting to work in this field.

On behalf of all of us at ABC, I offer Sylvia our warmest thanks for her visionary leadership and generous dedication of time and energy as a founding editor and during her tenure as ABC Editor. I am delighted to have worked together with Sylvia in this capacity, and look forward to new future collaborations and discussions, in science and in friendship.

Thank you Sylvia.

Aldo 